Research Article

\title{
Study on the Flow Mechanism of Shale Oil with Different Injection Media
}

\author{
Lanlan Yao, ${ }^{1,2}$ Zhengming Yang, ${ }^{1,2}$ Haibo Li, ${ }^{2}$ Bo Cai, ${ }^{3}$ Chunming He, ${ }^{3}$ and Debin Xia $\mathbb{D}^{1,2}$ \\ ${ }^{1}$ College of Engineering Science, University of Chinese Academy of Sciences, Beijing 101400, China \\ ${ }^{2}$ Institute of Percolation and Fluid Mechanics, China Petroleum Exploration and Development Research Institute, \\ Langfang 065007, China \\ ${ }^{3}$ Fracture Acidification Center of China Petroleum Exploration and Development Research Institute, Langfang 065007, China \\ Correspondence should be addressed to Debin Xia; xiadebin16@mails.ucas.edu.cn
}

Received 5 November 2020; Revised 6 July 2021; Accepted 27 July 2021; Published 20 August 2021

Academic Editor: Doo-Yeol Yoo

Copyright (c) 2021 Lanlan Yao et al. This is an open access article distributed under the Creative Commons Attribution License, which permits unrestricted use, distribution, and reproduction in any medium, provided the original work is properly cited.

\begin{abstract}
Chinese shale oil has high recoverable resources and great development potential. However, due to the limitation of development technology, the recovery rate of shale oil is not high. In this paper, the effects of different injection media on the development of shale oil reservoirs in Dongying formation, Qikou depression, Huanghua depression, and Bohai bay basin, were studied by means of imbibition and nitrogen flooding. Combining nuclear magnetic resonance (NMR) technology with imbibition and gas displacement experiments, the mechanism of shale injected formation water, active water (surfactant), and nitrogen was reproduced. The displacement process of crude oil under different injection media and injection conditions was truly demonstrated, and the relationship between different development methods and the pore boundaries used was clarified. A theoretical basis for the effective development of shale oil was provided. At the same time, Changqing tight oil cores with similar permeability to Dagang shale oil cores were selected for comparison. The results showed that, as the imbibition time of shale samples increased, the imbibition efficiency increased. Pores with $T_{2}<10 \mathrm{~ms}$ contributed the most to imbibition efficiency, with an average contribution greater than $90 \% .10 \mathrm{~ms}<T_{2}<100 \mathrm{~ms}$ and more than $100 \mathrm{~ms}$ pores contributed less to imbibition efficiency. Active water can change the wettability of shale, increase its hydrophilicity, and improve the efficiency of imbibition. The imbibition recovery ratio of injected active water was $17.56 \%$ higher than that of injected formation water. Compared with tight sandstone with similar permeability, the imbibition efficiency of shale was lower. As the nitrogen displacement pressure increased, the oil displacement efficiency also increased. The higher the shale permeability was, the greater the displacement efficiency would be. $T_{2}>100 \mathrm{~ms}$ pore throat of shale contributed to the main oil displacement efficiency, with an average oil displacement efficiency contribution of $63.16 \%$. And the relaxation interval $10<T_{2}<100 \mathrm{~ms}$ pore throat displacement efficiency contributed to $28.27 \%$. $T_{2}<10 \mathrm{~ms}$ pore throat contributed the least to the oil displacement efficiency, with an average oil displacement efficiency contribution of $8.58 \%$. Compared with tight sandstone with similar permeability, shale had lower oil displacement efficiency. The findings of this study can help for better understanding of the influence of different injection media on shale oil recovery effect.
\end{abstract}

\section{Introduction}

After tight oil, shale oil has become a research hotspot in the field of exploration and development. Compared with conventional sandstone, shale is dominated by nanoscale pores, with a special pore structure, complex rock composition, and ultra-low permeability $[1,2]$. In 2016 , the proven reserves of shale oil in the United States were 2.222 billion tons, of which Bakken's proven reserves of shale oil were 747 million tons, ranking first. The average daily output of shale oil commercial development in the United States reached 670,000 tons in 2017, and the average daily output in the first half of 2018 exceeded 800,000 tons [3]. In North America, the study of shale oil theory has become increasingly sophisticated [4-6]. Loucks et al. classified shale pores by scanning electron microscopy; then, shale pores were divided into three categories: inorganic intergranular pores, inorganic intragranular pores, and organic pores $[7,8]$. 
Labani et al. quantitatively characterized the pore structure of shale based on gas adsorption method, high-pressure mercury intrusion method, nuclear magnetic resonance method, and small-angle scattering method [9]. Chalmers et al. carried out a joint characterization of the pore size of several shales in North America by nitrogen adsorption and $\mathrm{CO}_{2}$ adsorption [10]. In terms of imbibition, the predecessors mainly explored the cause of fracturing fluid retention in shale reservoirs through spontaneous imbibition experiments $[11,12]$, but the spontaneous imbibition process had not been studied in depth. The shale oil revolution in North America has promoted the development of shale oil exploration and development theories in the world, and it also set off a wave of shale oil exploration and development in China [13-16]. Shale oil resources are mainly distributed in Meso-Cenozoic continental basins, such as Songliao Basin, Ordos Basin, Bohai Bay Basin, and Sichuan Basin.

Due to the difference between the type of continental shale oil resources in China and the type of marine shale oil resources in the United States, there is still a lack of suitable production technology, resulting in relatively low shale oil production in China and great development potential [17]. Although Chinese research pages on shale oil are increasing, the current research is currently focused on the field of microscopic pore structure characteristics. Wang et al. graded and evaluated shale reservoirs by means of average pore size, specific surface area, and chlorite relative content obtained by XRD and cryogenic nitrogen adsorption tests of whole rock [18]. Lu et al. used nuclear magnetic resonance technology to test the dynamic fluid of shale oil [19]. The results indicated that the content of the dynamic fluid in shale oil reservoir was very low and it was mainly stored in micron-level pores, with poor fluid mobility and great difficulty in development. Lu et al. used high-pressure mercury intrusion technology to characterize the micropore throat structure of shale oil reservoirs [20]. On this basis, shale oil reservoir classification evaluation standards and lower limits of reservoir formation were established. The micropore structure of shale oil reservoir is the basis of its reservoir evaluation and effective development [21, 22], and the evaluation of development mode and the range of pores is particularly important for the enhanced oil recovery of shale oil [23]. At present, the research on the oil production law under different injection media and different injection conditions is mainly focused on tight oil. Zhang et al. used nuclear magnetic resonance (NMR) technology to conduct spontaneous imbibition experiments on tight oil reservoirs; then, the contribution of pores of different sizes to imbibition recovery was analyzed quantitatively [24]. The conclusion was obtained that three reasonable ratios were conducive to imbibition recovery. $\mathrm{Li}$ et al. studied the effects of the pore structure of tight sandstone reservoirs on imbibition characteristics and self-priming oil displacement efficiency by means of mercury injection, scanning electron microscopy, and nuclear magnetic resonance (NMR) [25]. The results showed that the ratio of large pore throat determines the oil displacement efficiency, and the residual oil is mainly retained in the micropore throat. The higher the ratio of large hole throat was, the higher the efficiency of self-absorption oil displacement would be. Mannon and Chilingarian studied the relationship between the rate of water injection and absorption through laboratory experiments using models to simulate fractured matrix reservoirs [26]. The results showed that, under linear countercurrent conditions, the increase in water injection rate led to an increase in the rate of water absorption and an increase in the final recovery rate. Cuiec et al. found that the lower the permeability was, the stronger the permeability would be, and the potential of crude oil in the matrix system relying on imbibition in tight reservoirs was greater than that of medium-high permeability [27]. Li et al. used reservoir wettability contact angle experiments to characterize the lipophilicity of tuffaceous mudstone samples [28]. Zhang et al. found that the surfactants can promote the spontaneous imbibition of matrix shale [29]. Yang et al. applied NMR technology to physical model experiments and obtained a new method to calculate the mixed wettability index of tight oil reservoirs [30]. Zuwa and Omoregle determined the operating pore boundary of the injected medium displacing crude oil by mercury injection method and semipermeable separator method [31]. However, these two methods have difficulties in characterizing the fine pores of the tight reservoir, and they could not truly show the real displacement process of the injected medium and crude oil under different injection media and conditions.

Through a large number of literature surveys, it can be found that the previous studies on the flow mechanism of different injected media were mainly focused on tight oil reservoirs or shale gas reservoirs, and there were few studies on shale oil reservoirs $[32,33]$. In order to solve the above problems, this study took shale samples from Qikou sag of Huanghua depression, eastern Bohai Bay Basin, China, as the research object, and combined nuclear magnetic resonance (NMR) technology with physical simulation experiments to analyze the flow mechanism of shale oil in different injection media. First, physical simulation experiments of spontaneous imbibition and nitrogen displacement were established, and then the degree of crude oil recovery was analyzed by measuring the nuclear magnetic resonance spectra of rock samples under different imbibition times and gas flooding pressures, so as to provide a theoretical basis for the effective development of shale oil.

\section{Methods}

2.1. Principle of Nuclear Magnetic Resonance (NMR) Experiment. Nuclear magnetic resonance (NMR) is a common test and analysis method for reservoir description and evaluation based on the observation of hydrogen nuclear signals in rock pores, the direct measurement of pore fluid properties, the acquisition of reservoir physical-property related parameters, and the calculation of dynamic fluid parameters. In the field of shale oil reservoirs, the measurement error of many common testing methods has become larger, thus misleading the interpretation of shale oil reservoirs. The nuclear magnetic resonance (NMR) technique can be used as an approximate nondestructive technique to measure the pore structure of shale oil reservoirs [34]. 
When saturated oil, water, or oil-water rock samples are placed in a magnetic field, hydrogen atoms in the water will be affected by the magnetic field to produce polarized hydrogen atoms. This kind of nucleus has a certain magnetic moment. When this nucleus is in an RF (radio frequency) magnetic field, the hydrogen atoms oscillate in a phenomenon called nuclear magnetic resonance. When the applied RF magnetic field disappears, the oscillating hydrogen atom loses its energy source and relaxes in the pore space, its kinetic energy decreases with time, and the amplitude of oscillation decreases accordingly. The increasingly slow motion signal of the hydrogen atom core can be divided into $T_{1}$ and $T_{2}$ according to the decay rate, which, respectively, represent the longitudinal and transverse relaxation time. Since the longitudinal relaxation time is slow and the measurement has a large error, the measurement of NMR is generally the transverse relaxation time $T_{2}$ [35].

\subsection{Nuclear Magnetic Resonance (NMR) Laboratory} Apparatus. Recore-04 core NMR analyzer w developed by the institute of percolation, the Chinese academy of sciences, was used in the NMR experiment in this study. In the main test parameters, the echo interval was three hundred milliseconds. The number of echoes was one thousand twentyfour. The number of scanning was sixty-four. The waiting time was three thousand milliseconds. The gain was fifty. The influence of temperature on NMR results was reduced by measuring the standard sample before core NMR. All the NMR $T_{2}$ measurement experiments in this study took the above data as parameters.

\section{Geological Background}

3.1. Shale Oil Cores in Dagang. Huanghua depression is a sublevel depression in Bohai Bay Basin in eastern China. It is a rifting and depression basin developed in the mainland. The east and west sides of the depression are sandwiched by Chengning uplift and Cangxian uplift. Secondary fault depression of Qikou sag in Bohai gulf basin tectonic units, of the genus in formed since Cenozoic intracontinental extension basin. The main body is located in the center of Bohai bay basin. Paleogene system includes two sets of Shahejie and Dongying group formation. And Shahejie formation are further divided into a sand, the second member of the sand, and sand three sections. Among them, a sand is further divided into three subsections: sand below, sand in the middle, and sand above. The inclined direction of the slope in the southwest margin of Qikou Depression is the sedimentary environment of "overwater uplift-lake flatunderwater low uplift-lake bay-semideep lake-deep lake.” The slope direction is the interphase topography of "upliftdepression," and the overall environment is the closedsemiclosed wide brackish lake bay environment. The Chengning uplift, Gangxi uplift, Kongdian uplift, and Cangxian uplift have a weak influence on this area. Limestone and granulite are developed around the uplift, and lacustrine carbonate and shale deposits are widely developed in Huwan belt. There is a major development of carbonate shale, felsic shale, mixed shale, and shale. Clayey mineral composition is diversiform. It has higher brittleness mineral content, high-quality hydrocarbon source rocks, and hydrocarbon generation conditions. The shale is $10-40 \mathrm{~m}$ thick and 1,900-3,800 $\mathrm{m}$ deep and is in the stage of abundant hydrocarbon generation. According to the mass oil content, the shale oil resources amount is 365 million tons. As of early February 2019, the Guandong $1701 \mathrm{H}$ and Guandong $1702 \mathrm{H}$ horizontal shale oil wells in Dagang Oilfield had been spouted for more than 260 days, and the daily crude oil production had stabilized at $20-30 \mathrm{~m}^{3}$. The Guandong area had formed a battlefield for increasing reserves of 100 million tons [36].

3.2. Tight Sandstone Oil Cores in Changqing. The tight oil cores were taken from the Yanchang Formation in the Ordos Basin and mainly developed the semideep lacustrine facies area. The shale in the $7^{\text {th }}$ member of the Yanchang Formation and the tight sandstone in the $6^{\text {th }}$ member of the Yanchang Formation in the middle of the lake basin are the most typical ones. The tight oil in Ordos is mainly distributed in the center of a large depression lake basin in the Mesozoic era. The tight sandstone is in direct contact with high-quality hydrocarbon source rock hydrolyzation, and the oil source is sufficient. The generated oil and gas can be accumulated after short distance migration. The tight sandstone reservoirs in the basin are mainly terrigenous clastic rocks with complex lithology, mainly fine sand rocks, fine grain size, poor physical properties, and dense reservoirs. The tight oil in Ordos Basin has two key geological characteristics. First, the source and reservoir are symbiotic. The large area of the banded oil-bearing reservoir is distributed continuously, and there is no obvious trap and oilwater boundary. Second is nonbuoyancy accumulation and continuous filling of oil and gas. It is not affected by the obvious hydrodynamic effect. There is no unified oil-water interface and pressure system. Ordos Basin is characterized by large shale thickness and wide distribution range, and the interbedded clastic rocks are relatively developed, which has favorable geological conditions for the formation of tight oil. Physical parameters of shale and tight sandstone are shown in Table 1. Shale was taken from the main production horizon of Dagang shale reservoir. Due to the development of reservoir bedding, it was impossible to get a large number of regular cores. Therefore, several representative shale blocks were selected to conduct imbibition and gas flooding experiments [37].

\section{Experimental}

4.1. Experimental Study on Shale-Formation Water and Active Water Imbibition. The effects of injected water and injected active water (surfactant) on the development of shale oil were mainly analyzed by the spontaneous imbibition experiment of shale oil cores. The experimental equipment included a beaker (holding water), rubber band (fixing plastic film), plastic film, and mesh bag (holding broken core). Figure 1 shows the experiments setup of 
Table 1: Physical parameters of shale and tight sandstone.

\begin{tabular}{lcccccc}
\hline Lithology & The serial number & Length $(\mathrm{cm})$ & Diameter $(\mathrm{cm})$ & Dry weight $(\mathrm{g})$ & Porosity $(\%)$ & Permeability $(\mathrm{mD})$ \\
\hline Shale & 1 & 3.125 & 2.510 & 50.160 & 9.31 & 0.0137 \\
Shale & 2 & 1.510 & 2.500 & 20.750 & 9.30 & 0.0130 \\
Tight sandstone & 3 & 1.512 & 2.500 & 26.710 & 10.62 & 0.0154 \\
Shale & 4 & 2.230 & 2.507 & 25.453 & 8.99 & 0.0075 \\
Shale & 5 & 1.763 & 2.513 & 20.407 & 8.90 & 0.0612 \\
Tight sandstone & 6 & 3.820 & 2.524 & 30.147 & 9.00 & 0.0066 \\
\hline
\end{tabular}

spontaneous imbibition. The spontaneous imbibition oil recovery experiment is a physical simulation experiment. The spontaneous imbibition experiment of formation water and active water in saturated oil cores was designed, and the NMR $T_{2}$ spectrum was detected according to the preset time interval.

The steps were as follows: (1) firstly, the shale cores of no. 1 and no. 2 after oil washing were dried and vacuumed. Then, the saturated cores were pressurized with kerosene and finally fully saturated kerosene. After completion, $T_{2}$ NMR was performed. (2) Then, the cores of sample 1 and sample 2 were put into two beakers of $10,000 \mathrm{ppm}$ formation water with heavy water configuration (heavy water has no signal in the nuclear magnetic experiment and its main function is to eliminate the nuclear magnetic signal of water) and $10,000 \mathrm{ppm}$ active water with heavy water configuration to conduct spontaneous imbibition experiment. (3) The no. 3 Changqing tight oil core with a permeability similar to that of no. 1 shale was selected to conduct spontaneous imbibition experiments with formation water injected with 10,000 ppm salinity. The experimental results of the study on the difference of imbibition between tight oil and shale oil are shown in Figures 2-4 and Table 2.

In order to better analyze the microscopic mobilization law of imbibition, kerosene-saturated cores were used. Because the crude oil was a mixture, the magnetic signal in the core of the core was affected by both the pore size and the crude oil composition, so it was impossible to clearly analyze the microscopic law of imbibition. Nitrogen flooding mainly studied the microscopic law of oil production during the displacement process. Live oil mainly had a great influence on the experimental results when studying the effect of dissolved gas flooding. This study did not study dissolved gas flooding, so the use of kerosene did not affect the results. In addition, the Dagang shale had a low gas-oil ratio, and the reservoir had a small gas content, so there was no need to consider the influence of gas.

4.2. Experimental Study on Nitrogen Displacement of Shale. Nitrogen flooding experiments were carried out on saturated oil cores under different displacement pressures successively. When the displacement was over, the cores were taken out for NMR $T_{2}$ spectrum detection. The experimental equipment included a nitrogen bottle, core holder, precision pressure gauge, and hand pump. The nitrogen bottle provided the air source, and the hand pump and core holder provided the confining pressure for the cores. Figure 5 shows the gas flooding experiment setup.

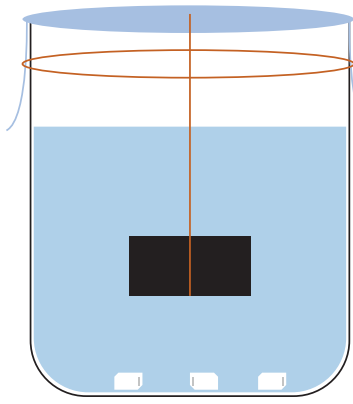

Figure 1: The experiment setup of spontaneous imbibition.

The steps were as follows: (1) Firstly, the shale cores of sample 4 and sample 5 after oil washing were dried, then they get vacuumed, and the cores were pressurized and saturated with kerosene until the cores were fully saturated with kerosene. Finally, the NMR $T_{2}$ was performed. (2) The cores were placed in the core holder to provide confining pressure. The displacement pressure point of the core holder was controlled by adjusting the nitrogen bottle. The confining pressure was controlled by the manual pump. The gas displacement experiment was carried out under the condition of keeping the net confining pressure unchanged. (3) After being taken out, the cores were weighed. And then the cores with different gas displacement pressures were dislocated for NMR $T_{2}$ spectrum detection. (4) The NMR $T_{2}$ spectra under different displacement pressures were plotted and analyzed according to the results of different displacement pressures. Sample 4 shale fractured after displacement at a pressure of $1.36 \mathrm{MPa}$, so it was impossible to obtain the data after displacement at $2.72 \mathrm{MPa}$. The gas flooding experiment of no. 6 Changqing tight sandstone with similar permeability to no. 4 shale was carried out under the same pressure to facilitate comparison with shale gas flooding results. The test results are shown in Table 3 and Figures 6 and 7.

\section{Results and Discussion}

5.1. The Influence of Formation Water and Active Water as Imbibition Media on the Degree of Recovery. Figures 2 and 3 are NMR spectra of the cores after imbibition. As can be seen from Figure 2, the NMR spectrum gradually changed from a single peak to a double peak with the increase of imbibition time. While the signal peak began to shift to the right, the spectrum span gradually increased. This indicated that the oil in the small pores of shale started to be absorbed into the large pores. The right wing of the right peak began to shift to 

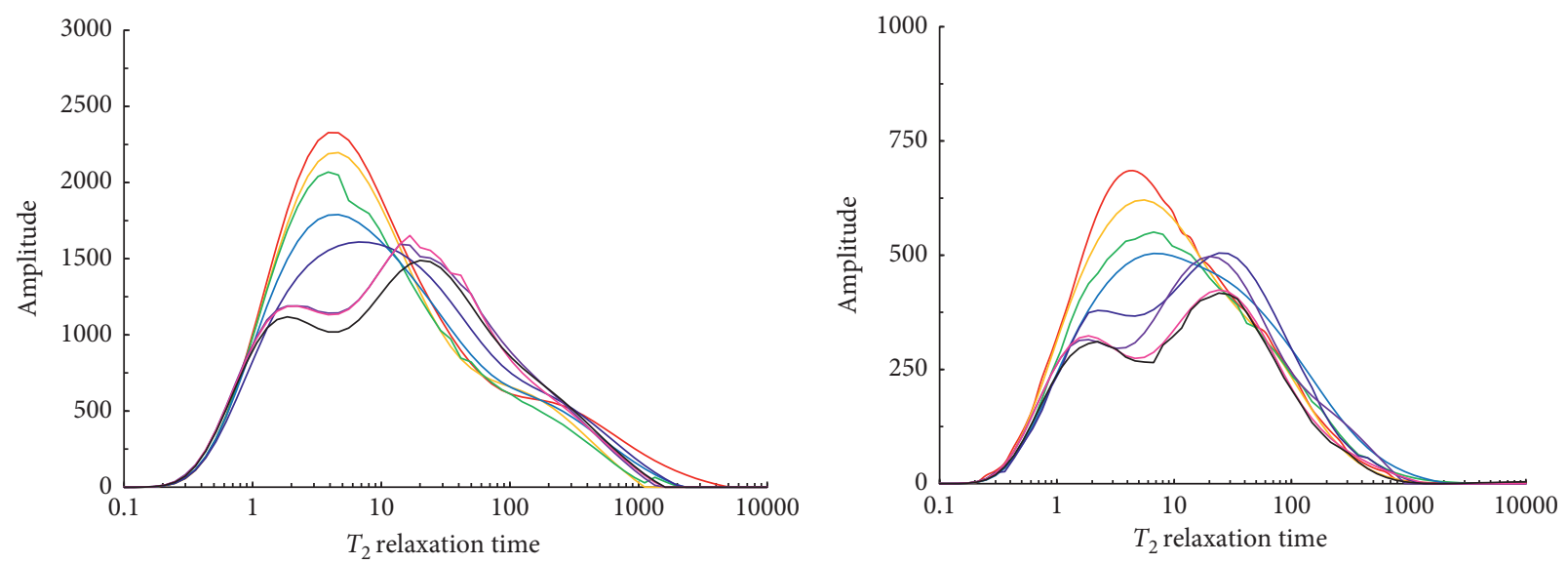

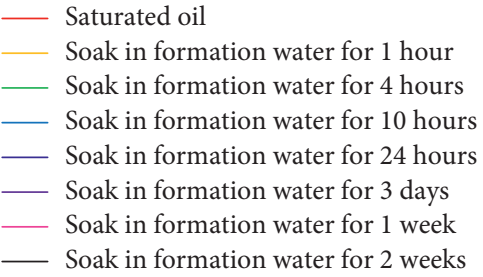

(a)

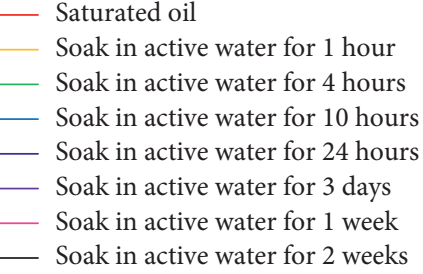

(b)

FIgURE 2: (a) Map of formation water imbibition of no. 1 shale. (b) Map of active water imbibition of no. 2 shale.

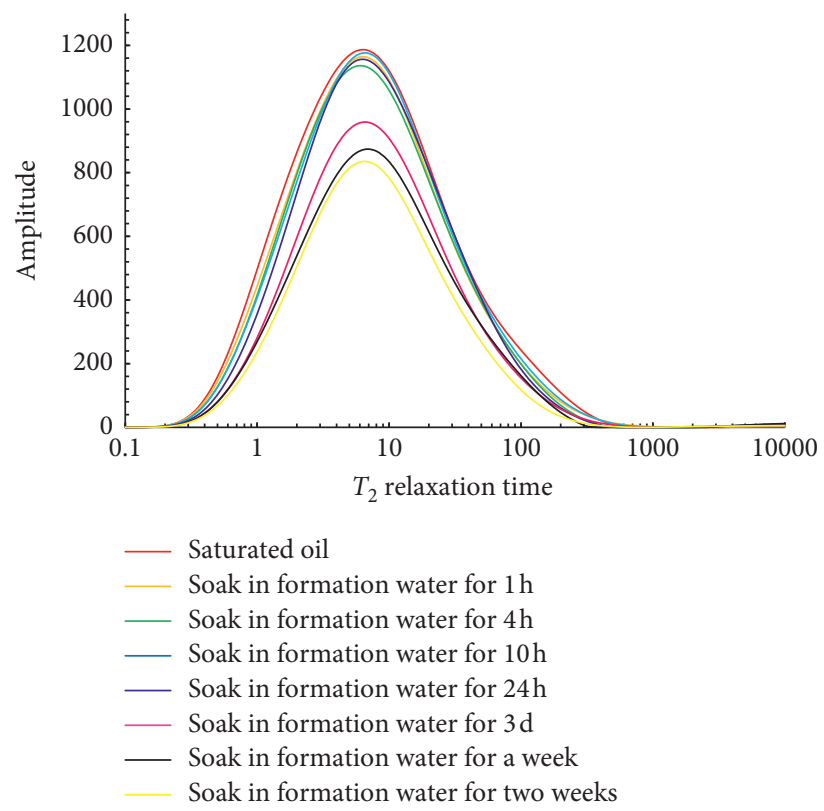

Figure 3: Map of formation water imbibition of no. 3 tight sandstone.

the right, especially at the intersection with the relaxation time axis. It indicated that microcracks were produced by the expansion of the shale due to imbibition. It was shown in Figure 6 that microcracks can also be seen by the naked eye on the surface of shale after imbibition. It could be seen from Figure 3 that when the tight sandstone oozed spontaneously, the NMR spectrum decreased steadily, indicating that the pore throat distribution of the tight sandstone was relatively uniform, and the spectrum span did not increase. It showed that the tight sandstone did not cause new microfractures due to water absorption and expansion. It can be seen from Figure 4 that, with the increase of the imbibition time, the shale recovery ratio kept increasing. Table 2 shows the contribution ratio of pore recovery degree at different relaxation times. It can be seen from Table 2 that the ultimate contribution of shale recovery ratio was the most pore with 


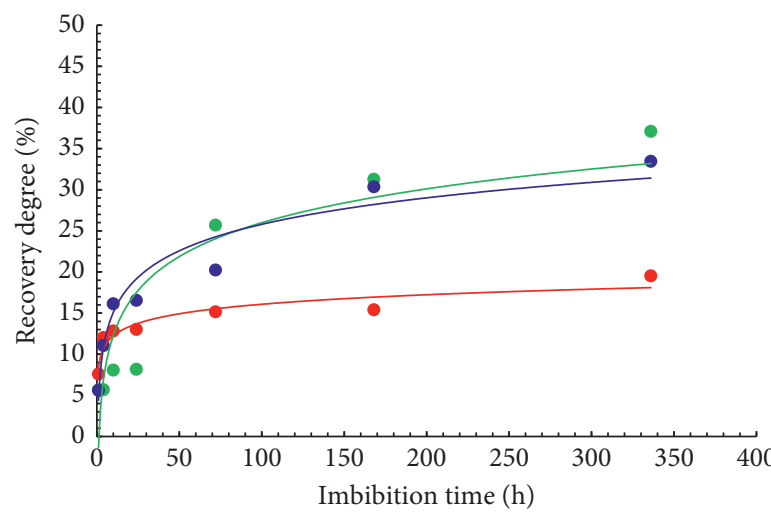

- Shale formation water

- Shale active water

- Tight sandstone formation water

Figure 4: The relationship between shale recovery and imbibition time.

TABLE 2: Contribution ratio of pore recovery degree at different relaxation times.

\begin{tabular}{|c|c|c|c|c|c|c|c|c|c|}
\hline \multirow{2}{*}{ Serial number } & \multirow{2}{*}{ Lithology } & \multirow{2}{*}{ Relaxation time (ms) } & \multicolumn{7}{|c|}{ Contribution ratio of recovery degree (\%) } \\
\hline & & & $1 \mathrm{~h}$ & $4 \mathrm{~h}$ & $10 \mathrm{~h}$ & $24 \mathrm{~h}$ & $3 \mathrm{~d}$ & One week & Two weeks \\
\hline \multirow{3}{*}{1} & \multirow{3}{*}{ Shale (formation water) } & $<10$ & 34.31 & 46.61 & 80.52 & 85.67 & 90.15 & 92.15 & 95.67 \\
\hline & & $10 \sim 100$ & 13.04 & 13.74 & 2.35 & 2.00 & 1.57 & 1.05 & 0.06 \\
\hline & & $>100$ & 52.63 & 39.64 & 17.13 & 12.33 & 8.28 & 6.80 & 4.27 \\
\hline \multirow{3}{*}{2} & \multirow{3}{*}{ Shale (active water) } & $<10$ & 74.80 & 80.44 & 85.74 & 90.47 & 95.66 & 97.53 & 97.88 \\
\hline & & $10 \sim 100$ & 12.31 & 12.88 & 9.98 & 6.95 & 1.86 & 0.56 & 0.23 \\
\hline & & $>100$ & 12.89 & 6.68 & 4.28 & 2.58 & 2.48 & 1.91 & 1.89 \\
\hline \multirow{3}{*}{3} & \multirow{3}{*}{ Tight sandstone (formation water) } & $<10$ & 51.66 & 54.31 & 57.08 & 59.64 & 66.74 & 65.53 & 62.51 \\
\hline & & $10 \sim 100$ & 33.09 & 21.54 & 22.21 & 20.99 & 28.78 & 27.85 & 30.49 \\
\hline & & $>100$ & 15.25 & 24.15 & 20.71 & 19.37 & 4.48 & 6.62 & 7.00 \\
\hline
\end{tabular}

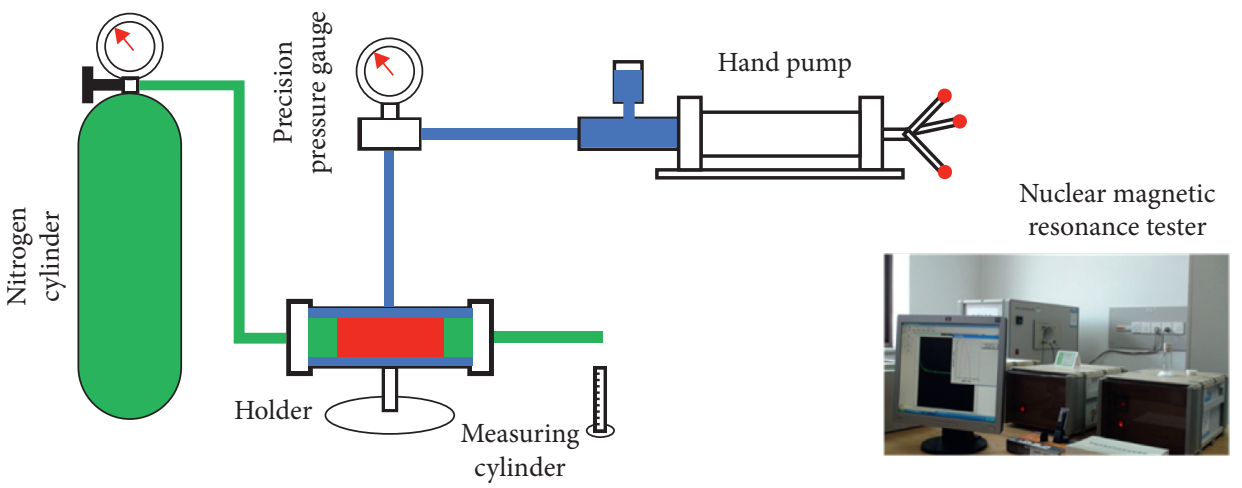

FIGURE 5: The gas flooding experiment setup.

relaxation time $T_{2}<10 \mathrm{~ms}$, and the average contribution of recovery ratio was more than $90 \%$. The pore with a relaxation time of $10 \mathrm{~ms} \sim 100 \mathrm{~ms}$ and the pore with a relaxation time of more than $100 \mathrm{~ms}$ contributed little to recovery. The imbibition recovery ratio of shale injected water was $19.54 \%$ and that of active water was $37.10 \%$. The imbibition recovery ratio of injected active water was $17.56 \%$ higher than that of injected water. Active water imbibition of shale can improve the recovery ratio in the pore range of $T_{2}<10 \mathrm{~ms}$, indicating that the oil saturation rate in this pore range decreased. According to the calculation method of mixed wettability index, the hydrophilicity and wettability of the shale were increased after the active water imbibition, so the final recovery ratio was also improved. Figure 4 shows the trend line of shale formation water and active water imbibition recovery over time. It can be seen that the imbibition rate of 
TABLE 3: Displacement efficiency under different displacement pressures.

\begin{tabular}{|c|c|c|c|c|c|c|c|}
\hline \multirow{2}{*}{ Serial number } & \multirow{2}{*}{ Lithology } & \multirow{2}{*}{$\Phi(\%)$} & \multirow{2}{*}{$K(\mathrm{mD})$} & \multicolumn{4}{|c|}{ Oil displacement efficiency (\%) } \\
\hline & & & & $0.34 \mathrm{MPa}$ & $0.68 \mathrm{MPa}$ & $1.36 \mathrm{MPa}$ & $2.7 \mathrm{MPa}$ \\
\hline 4 & Shale & 8.9900 & 0.0075 & 0.9600 & 2.7700 & 7.4800 & - \\
\hline 5 & Shale & 8.9000 & 0.0612 & 11.2300 & 12.2000 & 14.1900 & 15.1200 \\
\hline 6 & Tight sandstone & 9.0000 & 0.0049 & 3.8700 & 6.1000 & 8.2000 & 13.7100 \\
\hline
\end{tabular}

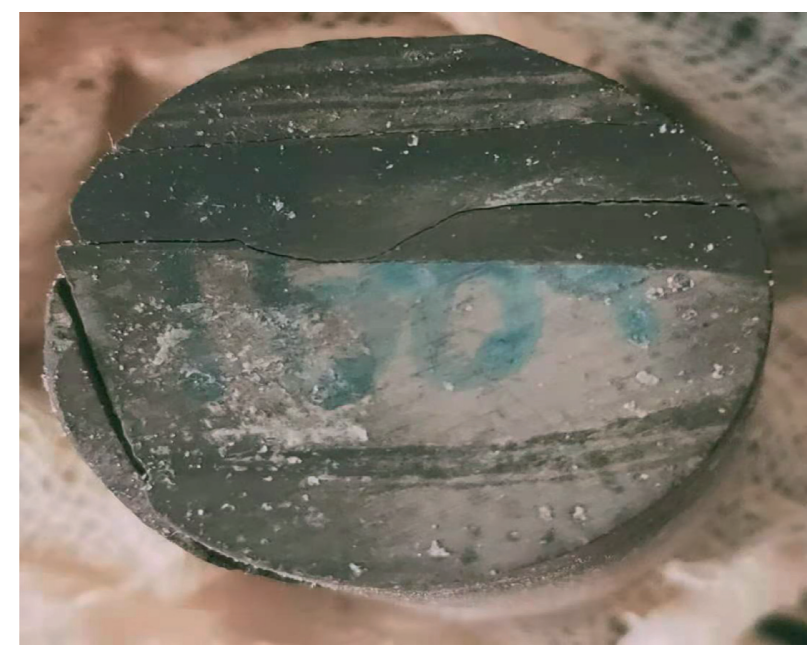

Figure 6: Microfracture morphology after spontaneous imbibition of shale formation water for two weeks.

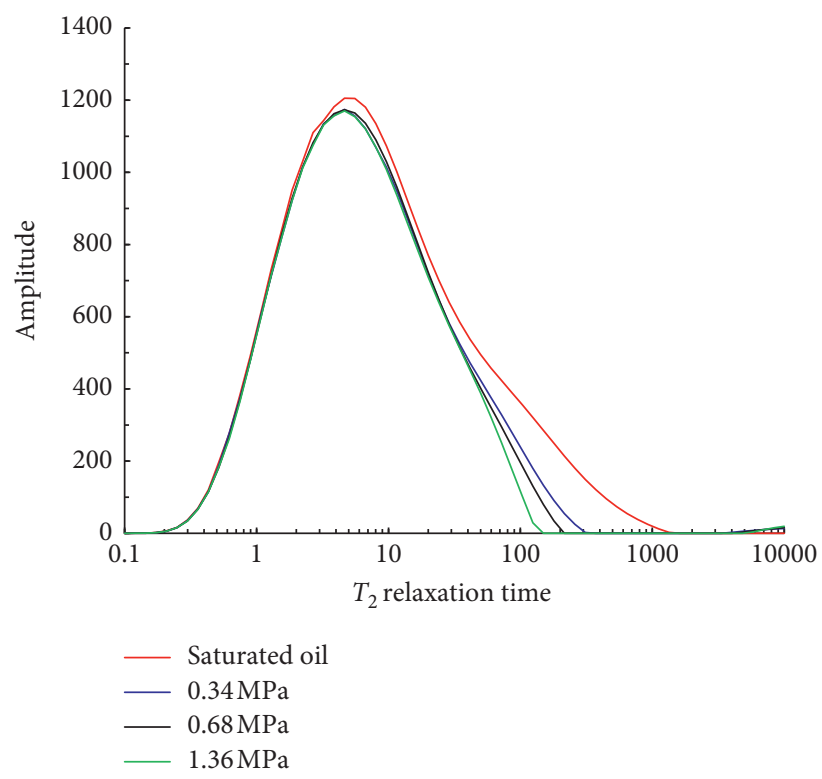

(a)

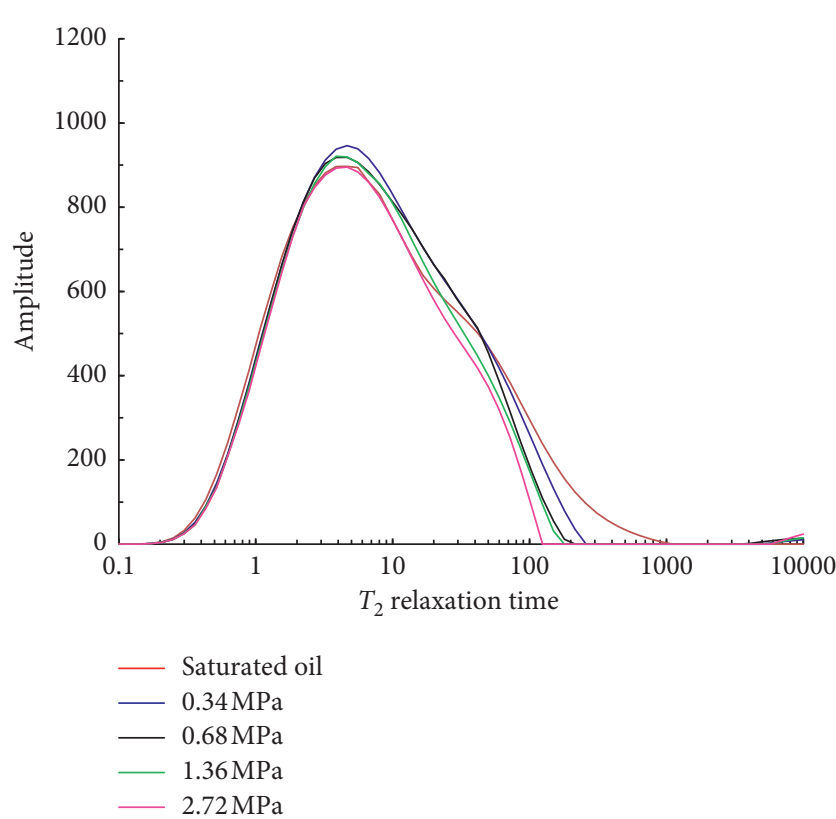

(b)

Figure 7: (a) Map of gas flooding of no. 4 shale. (b) Map of gas flooding of no. 5 shale.

shale in the formation was higher than that in the active water, but the shale in the formation imbibition ratio was balanced first than that in the active water imbibition; that is to say, the amount of imbibition in the active water was higher. Compared with the Changqing tight sandstone with the same permeability, the shale had lower ultimate recovery and less crude was used in the pore range of $10-100 \mathrm{~ms}$ and greater than $100 \mathrm{~ms}$. 


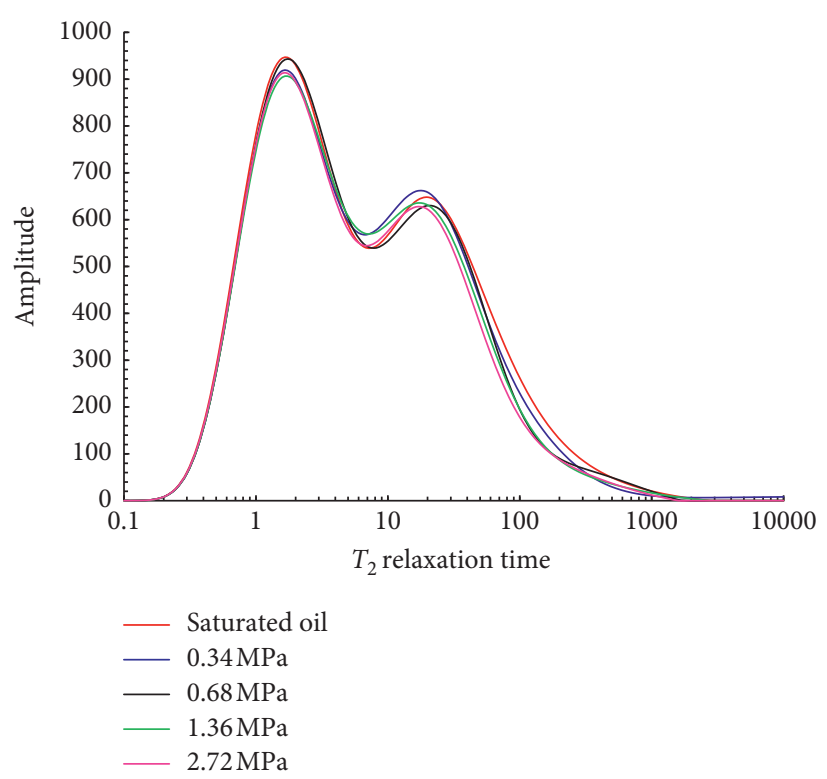

FIgUre 8: Map of gas flooding of no. 6 tight sandstone.

TABle 4: Contribution of pores with different relaxation times to oil displacement efficiency (\%).

\begin{tabular}{|c|c|c|c|c|c|c|}
\hline \multirow[t]{2}{*}{ Serial number } & \multirow[t]{2}{*}{ Lithology } & \multirow[t]{2}{*}{ Relaxation time (ms) } & \multicolumn{4}{|c|}{$\begin{array}{c}\text { Contribution of pores with different relaxation times to oil } \\
\text { displacement efficiency }(\%)\end{array}$} \\
\hline & & & $0.34 \mathrm{MPa}$ & $0.68 \mathrm{MPa}$ & $1.36 \mathrm{MPa}$ & $2.72 \mathrm{MPa}$ \\
\hline \multirow{3}{*}{4} & \multirow{3}{*}{ Shale } & $<10$ & 41.72 & 13.97 & 10.76 & - \\
\hline & & $10 \sim 100$ & 21.76 & 30.22 & 32.82 & - \\
\hline & & $>100$ & 37.12 & 55.81 & 56.42 & - \\
\hline \multirow{3}{*}{5} & \multirow{3}{*}{ Shale } & $<10$ & 26.73 & 10.48 & 6.40 & 1.61 \\
\hline & & $10 \sim 100$ & 15.48 & 20.87 & 23.71 & 27.73 \\
\hline & & $>100$ & 57.79 & 68.65 & 69.89 & 70.66 \\
\hline \multirow{3}{*}{6} & \multirow{3}{*}{ Tight sandstone } & $<10$ & 34.67 & 29.32 & 22.72 & 20.46 \\
\hline & & $10 \sim 10$ & 18.55 & 26.35 & 36.86 & 46.35 \\
\hline & & $>100$ & 46.78 & 44.33 & 40.42 & 33.19 \\
\hline
\end{tabular}

5.2. The Influence of Injected Nitrogen on the Development Effect. Figures 7 and 8 show the NMR spectra of nitrogen displacement of shale and sandstone under different pressures. As can be seen from Figures 7 and 8, the peak state of shale nuclear magnetic resonance was a single peak state, and the peak state of sandstone nuclear magnetic resonance was a double peak state, which indicated that the shale pore throat distribution was relatively simple, and most of them were small pore throats. Besides small pore throats, sandstone also had the distribution of large pore throats. Therefore, compared with sandstone, shale had a large specific surface area, and shale had a stronger adsorption effect on oil, with poor oil availability. Tables 3 and 4 show the cores gas flooding effect and pore recovery contribution of different relaxation times. Tables 3 and 4 show that, as the displacement pressure increased, the oil displacement efficiency also increased. The higher the shale permeability was, the greater the displacement efficiency would be. $T_{2}>100 \mathrm{~ms}$ pore throat of shale contributed to the main oil displacement efficiency; the average oil displacement efficiency contribution reached $63.16 \%$. And the relaxation interval $10<T_{2}<100 \mathrm{~ms}$ pore throat of shale displacement efficiency contributed to $28.27 \%$. $T_{2}<10 \mathrm{~ms}$ pore throat of shale contributed the least oil displacement efficiency, with an average oil displacement efficiency contribution of $8.58 \%$. Compared with tight sandstone with similar permeability, shale had lower oil displacement efficiency.

\section{Summary and Conclusions}

In this paper, nuclear magnetic resonance was combined with physical simulation experiments such as imbibition and nitrogen displacement to analyze the contribution of different injected media to the ultimate recovery ratio, so as to provide a scientific basis for the effective development of shale oil. The conclusions are as follows:

(1) As the imbibition time of shale samples increased, the imbibition efficiency increased. Pores with $T_{2}<10 \mathrm{~ms}$ 
contributed the most to imbibition efficiency, with an average contribution greater than $90 \%$. Active water can change the wettability of shale, increase its hydrophilicity, and improve the efficiency of imbibition. Compared with tight sandstone with similar permeability, shale had a lower imbibition efficiency.

(2) As the displacement pressure increased, the oil displacement efficiency also increased. The higher the shale permeability was, the greater the displacement efficiency would be. $T_{2}>100 \mathrm{~ms}$ pore of shale throat contributed to the main oil displacement efficiency, the average oil displacement efficiency contribution reached $63.16 \%$, and the relaxation interval $10<T_{2}<100 \mathrm{~ms}$ pore throat displacement efficiency contributed to $28.27 \% . T_{2}<10 \mathrm{~ms}$ pore throat contributed the least oil displacement efficiency, with an average oil displacement efficiency contribution of $8.58 \%$. Compared with tight sandstone with similar permeability, shale had lower oil displacement efficiency.

(3) Due to the small number of shale samples taken in this study, the research results cannot represent the entire shale block. It is recommended that the number of samples be increased next time for in-depth analysis.

\section{Data Availability}

The data used to support the findings of this study are available from the corresponding author upon request.

\section{Conflicts of Interest}

The authors declare that they have no conflicts of interest.

\section{Authors' Contributions}

Lanlan Yao conceived the experiment and conducted experimental work, drafted the manuscript, and made a series of modifications. Zhengming Yang helped analyze the experimental data. Haibo Li proposed experimental suggestions for improvement during the experiment. Bo Cai made suggestions for the manuscript, which greatly helped the completion of the thesis. Chunming He participated in the recording and collection of experimental data. All the authors gave approval for publication.

\section{Acknowledgments}

This work was supported by the Major National Oil and Gas Project (2017ZX05013-001), Major Basic Science and Technology research project of CNPC (2018B-4907), and Study on the technical mechanism of enhanced oil recovery of Ordos Basin and Jimsar Shale Oil (kt2021-09-05).

\section{References}

[1] J. B. Curtis, "Fractured shale-gas systems," AAPG Bulletin, vol. 86, no. 11, pp. 1921-1938, 2002.

[2] A. A. Hinai, R. Rezaee, L. Esteban, and M. Labani, "Comparisons of pore size distribution: a case from the Western
Australian gas shale formations," Journal of Unconventional Oil and Gas Resources, vol. 8, pp. 1-13, 2014.

[3] J. Xu, "U.S. comprehensively increases shale oil production," Petroleum Refining and Chemical Industry, vol. 9, p. 102, 2017.

[4] R. G. Loucks, R. M. Reed, S. C. Ruppel, and D. M. Jarvie, "Morphology, genesis, and distribution of nanometer-scale pores in siliceous mudstones of the mississippian barnett shale," Journal of Sedimentary Research, vol. 79, no. 12, pp. 848-861, 2009.

[5] C. H. Sondergeld, R. J. Ambrose, and C. S. Rai, "Microstructural studies of gas shales," in Proceedings of SPE Unconventional Gas Conference, Pennsylvania, USA, February 2010.

[6] R. M. Slatt and N. R. O’Brien, "Pore types in the Barnett and Woodford gas shales: contribution to understanding gas storage and migration pathways in fine-grained rocks," AAPG Bulletin, vol. 95, no. 12, pp. 2017-2030, 2011.

[7] R. G. Loucks, R. M. Reed, S. C. Ruppel, and U. Hammes, "Spectrum of pore types and networks in mudrocks and a descriptive classification for matrix-related mudrock pores," AAPG Bulletin, vol. 96, no. 6, pp. 1071-1098, 2012.

[8] B. Roychaudhuri, T. T. Tsotsis, and K. Jessen, "An experimental investigation of spontaneous imbibition in gas shales," Journal of Petroleum Science and Engineering, vol. 111, pp. 87-97, 2013.

[9] M. M. Labani, R. Rezaee, A. Saeedi, and A. A. Hinai, "Evaluation of pore size spectrum of gas shale reservoirs using low pressure nitrogen adsorption, gas expansion and mercury porosimetry: a case study from the Perth and Canning Basins, Western Australia," Journal of Petroleum Science and Engineering, vol. 112, pp. 7-16, 2013.

[10] G. R. Chalmers, R. M. Bustin, and I. M. Power, "Characterization of gas shale pore systems by porosimetry, pycnometry, surface area, and field emission scanning electron microscopy/transmission electron microscopy image analyses: examples from the Barnett, Woodford, Haynesville, Marcellus, and Doig units," AAPG Bulletin, vol. 96, no. 6, pp. 1099-1119, 2012.

[11] E. Ghanbari and H. Dehghanpour, "Impact of rock fabric on water imbibition and salt diffusion in gas shales," International Journal of Coal Geology, vol. 138, pp. 55-67, 2015.

[12] S. A. Sonnenberg and A. Pramudito, "Petroleum geology of the giant elm coulee field, Williston basin," AAPG Bulletin, vol. 93, no. 9, pp. 1127-1153, 2009.

[13] F. Rasdi and L. F. Chu, "Diagnosing fracture network pattern and flow regimes aids production performance analysis in unconventional oil reservoirs," in Proceedings of SPE/EAGE European Unconventional Resources Conference And Exhibition, pp. 20-22, Vienna, Austria, March 2012.

[14] S. M. Centurion, R. Cade, X. L. Luo et al., "Eagle ford shale: hydraulic fracturing completion and production trends Part III," in Proceedings of SPE Annual Technical Conference and Exhibition, p. 5627, New Orleans, LA, USA, September 2013.

[15] S. Liu, W. Ma, L. F. Jansa et al., "Characteristics of the shale gas reservoir rocks in the lower silurian longmaxi formation, east Sichuan Basin, China," Energy Exploration \& Exploitation, vol. 27, no. 2, pp. 2239-2252, 2013.

[16] J. Zhang, L. Lin, and Y. Li, "Classification and evaluation of shale oil," Earth Science Frontiers, vol. 19, no. 5, pp. 322-331, 2012.

[17] W. Wang, S. Lu, W. Tian et al., "Evaluation of shale reservoir classification in damintun depression of liaohe by using microscopic pore structure parameters," Journal of China 
University of Petroleum (Natural Science), vol. 40, pp. 12-19, 2016.

[18] Q. Sang, S. Zhang, C. Zhu et al., "Study on movable fluid of continental shale oil reservoir with NMR technology," China Sciencepaper, vol. 12, pp. 978-983, 2017.

[19] C. Zou, Z. Yang, J. Cui et al., "Formation mechanism, geological characteristics and development strategy of nonmarine shale oil in China," Petroleum Exploration and Development, vol. 40, no. 1, pp. 15-27, 2013.

[20] S. Lu, J. Li, P. Zhang et al., "Classification of microscopic porethroats and the grading evaluation on shale oil reservoirs," Petroleum Exploration and Development, vol. 45, no. 3, pp. 452-460, 2018.

[21] X. Zhao, L. Zhou, X. Pu et al., "Development and exploration practice of the concept of hydrocarbon accumulation in rifted-basin troughs: a case study of Paleogene Kongdian Formation in Cangdong sag, Bohai Bay Basin," Petroleum Exploration and Development, vol. 45, no. 6, pp. 1166-1176, 2018.

[22] W. Pan, S. Zhang, Z. Lun et al., "Experiment of the recoverable pore limits and tight oil developing methods," Petroleum Geology and Development in Daqing, vol. 35, pp. 155-158, 2016.

[23] Q. Zhou and G. Yang, "Status and prospects of shale oil \& gas exploration in the United States," International Petroleum Economics, vol. 26, no. 9, pp. 47-54, 2018.

[24] X. Zhang, H. Guo, and H. Li, "Experimental study on imbibition oil displacement of tight oil reservoir using NMR technology," Bulletin of Science and Technology, vol. 34, pp. 35-40, 2018.

[25] X. Li, X. Ren, and X. Luo, "Influence of pore structure of lowpermeability tight sandstone reservoir on imbibition characteristics," Oil \& Gas Geology and Recovery, vol. 25, pp. 115-121, 2018.

[26] R. W. Mannon and G. V. Chilingarian, "Experiments on effect of water-injection rate on imbibition rate in fractured reservoirs,” Energy Sources, vol. 1, no. 1, pp. 95-116, 1973.

[27] L. E. Cuiec, B. Bourbiaux, F. Kalaydjian et al., "Oil recovery by imbibition in low-permeability chalk," SPE Journal, vol. 9, no. 3, pp. 200-208, 1994.

[28] Y. Li, Y. Song, X. Xu et al., "The wettability and spontaneous imbibition characteristics of the tuffaceous shale reservoir of the 7th member of Yanchang Formation in Ordos Basin," Acta Petroleum, vol. 41, no. 10, pp. 72-80, 2020.

[29] F. Zhang, M. Song, X. Wu et al., "Characteristics of water wetting and imbibition of continental and marine shale," Science Technology and Engineering, vol. 19, no. 32, pp. 126132, 2019.

[30] Z. Yang, H. Huang, Y. Luo et al., "A new method for testing mixed wettability of tight reservoirs and its application," Acta Petroleum, vol. 38, no. 3, pp. 318-323, 2017.

[31] S. Zuwa and Omoregle, "Factors affecting the equivalency of different capillary pressure measurement techniques," SPE Journal, vol. 3, no. 1, pp. 146-155, 1986.

[32] M. Wei, Y. Duan, M. Dong, Q. Fang, and M. Dejam, "Transient production decline behavior analysis for a multifractured horizontal well with discrete fracture networks in shale gas reservoirs," Journal of Porous Media, vol. 22, no. 3, pp. 343-361, 2019.

[33] M. Dejam, "Advective-diffusive-reactive solute transport due to non-Newtonian fluid flows in a fracture surrounded by a tight porous medium," International Journal of Heat and Mass Transfer, vol. 128, pp. 1307-1321, 2019.
[34] J. Liu, S. Lu, C. Jiang et al., "Characterization of shale pore size distribution by NMR considering the influence of shale skeleton signals,” Energy \& Fuels, vol. 33, no. 6, pp. 6361-6372, 2019.

[35] I. Gupta, C. Rai, and C. Sondergeld, "Study impact of sample treatment and insitu fluids on shale wettability measurement using NMR," Journal of Petroleum Science and Engineering, vol. 176, pp. 352-361, 2019.

[36] Y. Jiang, H. Lu, H. Liu et al., "Characteristics and main controlling factors of hydrocarbon accumulation in Neogene in Raoyang Sag," Bohai Bay Basin, Acta Petroleum, vol. 32, no. 5, pp. 791-796, 2011.

[37] J. Liu, "High temperature and high pressure dynamic imbibition experiment of tight sandstone reservoir in Ordos Basin," Daqing Petroleum Geology and Development, vol. 39, no. 5, pp. 161-168, 2020. 